Research article Open Access

\title{
4-Hydroxynonenal induces apoptosis in human osteoarthritic chondrocytes: the protective role of glutathione-S-transferase
}

\author{
France Vaillancourt, Hassan Fahmi, Qin Shi, Patrick Lavigne, Pierre Ranger, Julio C Fernandes and \\ Mohamed Benderdour
}

\begin{abstract}
Orthopaedic Research Laboratory, Hôpital du Sacré-Cæur de Montréal, Department of Surgery, University of Montreal, 5400 Gouin Blvd. West, Montreal, QC, H4J 1C5, Canada

Corresponding author: Mohamed Benderdour, mohamed.benderdour@umontreal.ca

Received: 23 Jun 2008 Revisions requested: 15 Jul 2008 Revisions received: 16 Aug 2008 Accepted: 9 Sep 2008 Published: 9 Sep 2008

Arthritis Research \& Therapy 2008, 10:R107 (doi:10.1186/ar2503)

This article is online at: http://arthritis-research.com/content/10/5/R107

(C) 2008 Vaillancourt et al.; licensee BioMed Central Ltd.

This is an open access article distributed under the terms of the Creative Commons Attribution License (http://creativecommons.org/licenses/by/2.0), which permits unrestricted use, distribution, and reproduction in any medium, provided the original work is properly cited.
\end{abstract}

\begin{abstract}
Introduction 4-Hydroxynonenal (HNE) is one of the most abundant and reactive aldehydes of lipid peroxidation products and exerts various effects on intracellular and extracellular signalling cascades. We have previously shown that HNE at low concentrations could be considered as an important mediator of catabolic and inflammatory processes in osteoarthritis (OA). In the present study, we focused on characterizing the signalling cascade induced by high HNE concentration involved in cell death in human OA chondrocytes.
\end{abstract}

Methods Markers of apoptosis were quantified with commercial kits. Protein levels were evaluated by Western blotting. Glutathione (GSH) and ATP levels were measured with commercial kits. Glucose uptake was assessed by 2-deoxy-D$\left[{ }^{3} \mathrm{H}\right]$-glucose. The role of GSH-S-transferase A4-4 (GSTA4-4) in controlling HNE-induced chondrocyte apoptosis was investigated by chondrocyte transfection with small interfering RNA (siRNA) or with the expression vector of GSTA4-4.

Results Our data showed that HNE at concentrations of up to $10 \mu \mathrm{M}$ did not alter cell viability but was cytotoxic at concentrations of greater than or equal to $20 \mu \mathrm{M}$. HNE-induced chondrocyte death exhibited several classical hallmarks of apoptosis, including caspase activation, cytochrome $c$ and apoptosis-induced factor release from mitochondria, poly (ADPribose) polymerase cleavage, Bcl-2 downregulation, Bax upregulation, and DNA fragmentation. Our study of signalling pathways revealed that HNE suppressed pro-survival Akt kinase activity but, in contrast, induced Fas/CD95 and p53 expression in chondrocytes. All of these effects were inhibited by an antioxidant, $\mathrm{N}$-acetyl-cysteine. Analysis of cellular energy and redox status showed that HNE induced ATP, NADPH, and GSH depletion and inhibited glucose uptake and citric acid cycle activity. GSTA4-4 ablation by the siRNA method augmented HNE cytotoxicity, but, conversely, its overexpression efficiently protected chondrocytes from HNE-induced cell death.

Conclusion Our study provides novel insights into the potential mechanisms of cell death in OA cartilage and suggests the potential role of HNE in OA pathophysiology. GSTA4-4 expression is critically important for cellular defence against oxidative stress-induced cell death in OA cartilage, possibly by HNE elimination.

\section{Introduction}

Osteoarthritis $(O A)$ is a degenerative disease characterized by the loss and abnormal remodelling of cartilage extracellular matrix (ECM) $[1,2]$. Changes in matrix quality stem from the failure of chondrocytes to maintain a balance between protein synthesis and degradation. Chondrocytes are the only cell type found in mature cartilage, and their death may contribute to metabolic and structural changes in OA cartilage. Depend-

AIF: apoptosis-inducing factor; ATF/CRE: activating transcription factor/cAMP response element; Col II: type II collagen; COX-2: cyclooxygenase-2; DMEM: Dulbecco's modified Eagle's medium; ECM: extracellular matrix; EDTA: ethylenediaminetetraacetic acid; ELISA: enzyme-linked immunosorbent assay; FBS: fetal bovine serum; GSH: glutathione; GSSG: oxidized glutathione; GSTA4-4: glutathione-S-transferase A4-4; HNE: 4-hydroxynonenal; iNOS: inducible nitric oxide synthase; LPO: lipid peroxidation; MMP-13: matrix metalloproteinase-13; mNADP+-ICDH: mitochondrial NADP+dependent isocitrate dehydrogenase; MTT: 3-(4,5-dimethylthiazol-2-yl)-2,5-diphenyltetrazolium bromide; NAC: N-acetyl-cysteine; NF-kB: nuclear factor-kappa B; NO: nitric oxide; OA: osteoarthritis; PARP: poly (ADP-ribose) polymerase; PBS: phosphate-buffered saline; ROS: reactive oxygen species; siRNA: small interfering RNA. 
ing upon the region being examined, cartilage may be devoid of chondrocytes, presumably as a result of cell death, or contain clusters of chondrocytes that have undergone division, possibly in response to ECM depletion [2]. The superficial zones of OA cartilage contain empty lacunae, fragmented chondrocytes, and nuclear condensation [3]. Several studies have revealed increased apoptotic cell death in lesional areas compared with non-lesional areas in cartilage from the same OA patient, while apoptotic cells are rarely seen in normal cartilage [4]. In an experimental mouse model of OA, it has been shown that chondrocyte apoptosis in articular cartilage is correlated with age and disease severity [5]. In addition to cells with ultrastructural features of apoptosis, human OA cartilage contains cells that appear necrotic. Since cartilage does not have mononuclear phagocytes and is avascular, dead cells or apoptotic bodies are not removed but remain in the lacunae, where they disintegrate and release their contents. Ultrastructural evidence suggests that disintegration of chondrocytes in articular cartilage may lead to the formation of membraneenclosed structures resembling matrix vesicles $[3,6]$. These structures, which are remnants of dead cells, may in fact be apoptotic bodies and may contribute to matrix mineralization or degradation in OA.

Oxidative stress has been at the centre of the pathophysiological scene of OA disease over the past 30 years. Alterations in mitochondrial redox metabolism and respiratory functions may elicit the increased production of reactive oxygen species (ROS) in chondrocytes. Besides causing degradation [7] or inhibiting the synthesis of cartilage matrix [8], ROS may induce chondrocyte apoptosis. Nitric oxide (NO) has long been considered as the primary inducer of chondrocyte apoptosis mediated by caspase-3 and tyrosine kinase activation [9]. However, it has become clear that NO by itself cannot initiate apoptosis and that the concomitant production of superoxide anion is required [10], indicating a role for peroxinitrite in this process. In addition, there is a significant correlation between the level of NO generation and the prevalence of apoptotic cells in cartilage tissue during experimentally induced OA in rabbits [11].

Aldehydes are produced from ROS- and NO-induced lipid peroxidation (LPO) of membrane polyunsaturated fatty acids. Similar to free radicals, aldehydes are electrophiles that bind to nucleophilic groups of proteins, (amino)phospholipids, and nucleic acids, but their relatively longer half-life makes them candidates for the propagation of damage to neighbouring cells. Among the aldehydes, 4-hydroxy-2-alkenals, such as 4hydroxynonenal (HNE), are considered to be the most reactive species because of their $\alpha, \beta$-double bond [12]. This aldehyde is highly reactive with a variety of biomolecules, such as proteins, lipids, and nucleic acids, contributing to the pathogenesis of human chronic diseases [13]. Like ROS, HNE can also induce, in many cell types of different origins, various biological effects, such as alterations in cell proliferation, cell cycle procession, and apoptosis [14,15]. Studies have shown that antioxidant agents such as $N$-acetyl-cysteine (NAC) or glutathione-S-transferase A4-4 (GSTA4-4) overexpression suppress HNE production and inhibit the apoptotic process in several cell lines induced by this aldehyde $[16,17]$. In a recent study, we observed that the level of HNE protein adducts is higher in OA synovial fluid compared with normal subjects [18]. Moreover, we have demonstrated that, in OA cartilage, HNE can induce transcriptional as well as post-translational modifications of type II collagen (Col II) and matrix metalloproteinase13 (MMP-13), resulting in cartilage ECM degradation. Additionally, HNE can selectively induce cyclooxygenase-2 (COX2) expression via ATF/CRE (activating transcription factor/ cAMP response element) activation and inhibit the inducible form of NO synthase (iNOS) via nuclear factor-kappa B (NF$\kappa B)$ inactivation in human chondrocytes [19]. The objective of this study, which expands on our previous works, was to investigate the mechanism of HNE-induced apoptotic cell death in human $\mathrm{OA}$ chondrocytes. In addition, we evaluated the role of NAC treatment and GSTA4-4 overexpression in the protection against chondrocyte apoptosis induced by HNE.

\section{Materials and methods}

Specimen selection and chondrocyte culture

Cartilage specimens were obtained from OA patients who underwent total knee arthroplasty $(64 \pm 9$ years, mean \pm standard error, $n=34$ ). Diagnoses were established according to American College of Rheumatology criteria [20]. OA cartilage (femoral condyles and tibial plateaus) was obtained under aseptic conditions and carefully dissected from the underlying bone in each specimen. This project and the informed consent form were approved by the institutional Ethics Committee Board of the Hôpital du Sacré-Coeur de Montréal. OA chondrocytes were released from cartilage explants as described previously [18]. Isolated chondrocytes were seeded at high density in culture flasks until confluence in Dulbecco's modified Eagle's medium (DMEM) supplemented with $10 \%$ heat-inactivated fetal bovine serum (FBS) and 100 $\mathrm{U} / \mathrm{mL}$ penicillin/100 $\mathrm{mg} / \mathrm{mL}$ streptomycin (Invitrogen Canada Inc, Burlington, ON, Canada). First-passage chondrocytes were seeded in culture plates at $10^{5} \mathrm{cells} / \mathrm{cm}^{2}$ and incubated for 48 hours in the above medium. Before the experiments, the medium was replaced by fresh medium containing $2 \%$ FBS and treated as indicated in the experimental protocols.

\section{Cell viability}

HNE-induced chondrocyte cytotoxicity was evaluated by MTT (3-[4,5-dimethylthiazol-2-yl]-2,5-diphenyltetrazolium bromide) assay [21]. Tests were performed in 96-well plates. Briefly, chondrocytes were incubated for 16 hours with increasing concentrations ( 0 to $30 \mu \mathrm{M}$ ) of HNE (Cayman Chemical Company, Ann Arbor, MI, USA) or with $30 \mu \mathrm{M}$ HNE for increasing times of incubation in the presence or absence of $200 \mu \mathrm{M}$ NAC (Sigma-Aldrich, Oakville, ON, Canada). To explore the signalling cascade in HNE-induced cell death, cells were incubated for 1 hour with the inhibitor of poly (ADP-ribose) 
polymerase-1 (PARP-1), 5-iodo-6-amino-1,2-benzopyrone, at 50 and $100 \mu \mathrm{M}\left(\mathrm{INH}_{2} \mathrm{BP}\right.$; Sigma-Aldrich) or with anti-Fas/ CD95 antibody at $20 \mu \mathrm{g} / \mathrm{mL}$, followed by another incubation for 16 hours with $30 \mu \mathrm{M} \mathrm{HNE}$. Then, the cells were incubated with $0.5 \mathrm{mg} / \mathrm{mL}$ MTT for 15 minutes at $37^{\circ} \mathrm{C}$. Thereafter, 100 $\mu \mathrm{L}$ of solubilization solution (0.04 $\mathrm{M} \mathrm{HCl}$-isopropanol) was added. The amount of MTT formazan product was quantified by measuring of optical density at $570 \mathrm{~nm}$ with a microplate reader (BioTek Instruments, Winooski, VT, USA).

\section{Nuclear morphology study for apoptosis}

Apoptotic nuclear morphology was assessed by Hoechst 33258 incorporation (Sigma-Aldrich). Briefly, chondrocytes $\left(10^{5} \mathrm{cells} / \mathrm{cm}^{2}\right)$ were treated with or without $30 \mu \mathrm{M}$ HNE for 16 hours. The cells were fixed with $4 \%$ paraformaldehyde at room temperature for 15 minutes and then washed and stained with $10 \mu \mathrm{g} / \mathrm{mL}$ Hoechst 33258 in phosphate-buffered saline (PBS) at room temperature for 10 minutes. Hoechststained cells were analyzed by fluorescence microscopy.

\section{Measurement of caspase activities}

Enzymatic caspase-8, -9 , and -3 activities were measured with commercial kits. Chondrocytes $\left(10^{5} \mathrm{cells} / \mathrm{cm}^{2}\right)$ were treated with $30 \mu \mathrm{M}$ HNE for increasing incubation times ( 0 to 16 hours). To measure caspase- 8 and -9 activities, the cells were washed with PBS and resuspended in $100 \mu \mathrm{L}$ of lysis buffer (R\&D Systems, Minneapolis, MN, USA), left on ice for $10 \mathrm{~min}$ utes, and centrifuged. Protein concentration of the supernatants was measured according to the bicinchoninic acid method (Pierce, Rockford, IL, USA). Total proteins $(50 \mu \mathrm{g})$ were reacted with $200 \mu \mathrm{M}$ IETD-pNA or LEHD-pNA substrate in the presence of $100 \mu \mathrm{L}$ of reaction buffer. To quantitate caspase-3 activity, the cells were washed with PBS and lysed in $100 \mu \mathrm{L}$ of lysis buffer (Sigma-Aldrich), left on ice for $15 \mathrm{~min}$ utes, and centrifuged. Total proteins $(5 \mu \mathrm{g})$ were reacted with $200 \mu \mathrm{M}$ DEVD-pNA substrate in the presence of $100 \mu \mathrm{L}$ of reaction buffer. After 16 hours of incubation at $37^{\circ} \mathrm{C}, p$ nitroanilide release was measured at $405 \mathrm{~nm}$ for caspase-3, 8 , and -9 .

\section{Quantitation of Bcl-2}

Chondrocytes $\left(10^{5}\right.$ cells $\left./ \mathrm{cm}^{2}\right)$ were treated with $30 \mu \mathrm{M}$ HNE for increasing incubation times ( 0 to 16 hours). The protein expression of the antiapoptotic Bcl-2 was assayed in cell extracts with a Bcl-2 enzyme-linked immunosorbent assay (ELISA) kit (catalogue number QIA23; Calbiochem, now part of EMD Biosciences, Inc., San Diego, CA, USA) according to the manufacturer's instructions. The Bcl-2 level was expressed in units per milligram of protein.

\section{Measurement of DNA fragmentation}

Cytoplasmic histone-associated DNA fragments were quantitated with a Cell Death Detection ELISAPLUS kit (Roche Applied Science, Laval, QC, Canada) according to the manufacturer's recommendations. Briefly, chondrocytes $\left(2 \times 10^{6}\right.$ cells) were treated for 16 hours with increasing HNE concentrations ( 0 to $30 \mu \mathrm{M})$ with or without $200 \mu \mathrm{M}$ NAC. After incubation, the cells were lysed with lysis buffer for 30 minutes and centrifuged at $200 \mathrm{~g}$ for 10 minutes. The supernatant and a mixture of anti-histone-biotin and anti-DNA-peroxidase were added to streptavidin-coated microplates and incubated for 2 hours at room temperature. After adding the substrate, absorbance was measured at $405 \mathrm{~nm}$.

\section{Quantitation of cytochrome c release in cytosolic fractions}

To measure cytochrome $c$ release, chondrocytes $\left(1 \times 10^{6}\right.$ cells) were treated for 16 hours with increasing HNE concentrations $(0$ to $30 \mu \mathrm{M}$ ) with or without $200 \mu \mathrm{M} \mathrm{NAC}$, washed with PBS, and resuspended in $1 \mathrm{~mL}$ of buffer $(220 \mathrm{mM}$ mannitol, $70 \mathrm{mM}$ sucrose, $10 \mathrm{mM}$ Hepes $\mathrm{KOH}, \mathrm{pH} 7.4,10 \mathrm{mM}$ ethylenediaminetetraacetic acid [EDTA], 10\% glycerol). The cell suspension was incubated on ice for 15 minutes and centrifuged at $10,000 \mathrm{~g}$ for 15 minutes. The pellet containing the mitochondria was resuspended in $200 \mu \mathrm{L}$ of the above buffer and served to assess citric acid activity as described below. Cytochrome $c$ level was measured in cytosolic fractions (supernatants) with a Cytochrome c ELISA kit (EMD Biosciences, Inc.) according to the manufacturer's directions. Cytochrome $c$ level was expressed in nanograms per milligram of protein.

\section{Citric acid cycle activity}

Mitochondrial $\mathrm{NADP}^{+}$-dependent isocitrate dehydrogenase (mNADP+-ICDH) activity was assessed in mitochondrial fractions prepared, as described above, from chondrocytes treated with $30 \mu \mathrm{M}$ HNE for 16 hours. The assay was performed in the presence of $5 \mathrm{mM}$ isocitrate, $1 \mathrm{mM}$ NADP, and $2 \mathrm{mM} \mathrm{MgCl}$. Activities were expressed in units per milligram of protein, where 1 unit was defined as the amount of enzyme catalyzing the conversion of $1 \mu \mathrm{mol}$ substrate per minute at $37^{\circ} \mathrm{C}$.

\section{Quantitation of ATP level}

ATP level was assessed in cellular extracts from chondrocytes treated with $30 \mu \mathrm{M}$ HNE for 16 hours with an ATP Assay kit from EMD Biosciences, Inc. The results were expressed as picomoles per milligram of proteins.

\section{Quantification of reduced glutathione and oxidized glutathione levels}

Chondrocytes $\left(2 \times 10^{6}\right.$ cells $)$ were incubated for increasing time periods ( 0 to 16 hours) with $30 \mu \mathrm{M}$ HNE. The cells were washed with PBS and centrifuged at $800 \mathrm{~g}$ for 5 minutes. Pellets were resuspended in buffer $(0.4 \mathrm{M}$ 2-[N-morpholino] ethanesulphonic acid, $0.1 \mathrm{M}$ phosphate, $2 \mathrm{mM}$ EDTA) and centrifuged at $10,000 \mathrm{~g}$ for 15 minutes. Glutathione (GSH) and oxidized GSH (GSSG) levels were quantified with a Glutathione Assay Kit (Cayman Chemical Company) according to 
the manufacturer's directions. Values were expressed as the GSSG/[GSSG+GSH] ratio.

\section{Western blot analysis}

Chondrocytes were incubated for increasing time periods ( 0 to 16 hours) with $30 \mu \mathrm{M} \mathrm{HNE}$ or with increasing concentrations of HNE (0 to $30 \mu \mathrm{M})$ for 16 hours with or without $200 \mu \mathrm{M}$ NAC. Cellular protein extract $(20 \mu \mathrm{g})$ or nuclear protein $(5 \mu \mathrm{g})$, isolated as previously described [19], was subjected to discontinuous $4 \%$ to $12 \%$ SDS-PAGE as previously described [18]. The primary antibodies used were rabbit anti-human PARP, rabbit anti-human apoptosis-inducing factor (AIF), rabbit anti-human Bax, rabbit anti-human caspase-3, -9, anti-Akt (EMD Biosciences, Inc.), rabbit anti-human caspase-8, antip53, and mouse anti-human Fas/CD95 (Santa Cruz Biotechnology, Santa Cruz, CA, USA), and anti-GSTA4-4 (Abnova, Taipei, Taiwan). After serial washes, primary antibodies were detected by goat anti-rabbit IgG or goat anti-mouse IgG conjugated to horseradish peroxidase (Jackson ImmunoResearch Laboratories, Inc., West Grove, PA, USA). Specific signals were visualized with enhanced chemiluminescence detection kits (Pierce).

\section{Plasmids and transient GSTA4-4 transfection}

GSTA4-4 small interfering RNA (siRNA) and randomly sequenced siRNA as negative controls were purchased from Ambion (Austin, TX, USA). Wild-type and mutant GSTA4-4 expression plasmids were generously provided by Dr Sanjay Awasthi [17] (University of North Texas Health Science Center, Fort Worth, TX, USA). Subconfluent chondrocytes were transiently transfected by Lipofectamine $2000^{\mathrm{TM}}$ reagent (Invitrogen Canada Inc) according to the manufacturer's protocol. Briefly, transfections were conducted for 6 hours with DNA lipofectamine complexes containing $10 \mu \mathrm{L}$ of lipofectamine reagent, 100 nM GSTA4-4 siRNA (a mixture of three siRNAs targeting the GSTA4-4 gene) or randomly sequenced siRNA, or $2 \mu \mathrm{g}$ of DNA plasmid and $0.5 \mu \mathrm{g}$ of pCMV- $\beta$-gal (as a control of transfection efficiency). After washing, experiments were performed in 2\% FBS fresh medium supplemented or not supplemented with $30 \mu \mathrm{M} \mathrm{HNE}$. Then, cell viability and GSTA4-4 expression were analyzed by the MTT method and Western blotting, respectively, as described previously. $\beta$-gal level was measured with ELISA kits from Roche Diagnostics Canada (Laval, QC, Canada).

\section{Glucose uptake}

Chondrocytes were cultured for 16 hours in 24-well plates at $5 \times 10^{5}$ cells per well in $2 \%$ FBS/DMEM in the presence or absence of $30 \mu \mathrm{M}$ HNE. The culture media were replaced by $2 \% \mathrm{FBS} /$ glucose-free DMEM containing $10 \mu \mathrm{Ci} / \mathrm{mL}$ 2-deoxy$\mathrm{D}-[3 \mathrm{H}]$-glucose. Then, plates were incubated for 20 minutes at $37^{\circ} \mathrm{C}$. Subsequently, the media were aspirated and the cells were washed three times with cold PBS. They were then lysed with $400 \mu \mathrm{L} /$ well of cell death lysis buffer (EMD Biosciences, Inc.) for 15 minutes. Volumes of $300 \mu \mathrm{L}$ of cell lysates were transferred to scintillation vials, and radioactivity was measured by scintillation counting. The data are expressed as counts per minute (cpm) per milligram of proteins.

\section{Statistical analysis}

Results were expressed as the mean \pm standard error of the mean of eight specimens, and assays were performed in three independent experiments. Statistical analysis was performed using the two-tailed paired Student $t$ test, and a difference of less than or equal to 0.05 was considered significant.

\section{Results \\ HNE caused cell death in human osteoarthritis chondrocytes}

To investigate the effect of HNE on chondrocyte apoptosis, we first documented HNE cytotoxicity by MTT assay. After 16 hours of incubation, up to $10 \mu \mathrm{M}$ HNE did not alter cell viability, but 20 and $30 \mu \mathrm{M}$ HNE was cytotoxic and significantly decreased cell viability by approximately 50\% and 52\%, respectively. Furthermore, pre-treatment with $200 \mu \mathrm{M}$ NAC for 1 hour before adding $30 \mu \mathrm{M}$ HNE (Figure 1a) completely prevented $\mathrm{HNE}$-induced cell death. However, the addition of antiFas/CD95 $(20 \mu \mathrm{g} / \mathrm{mL})$ (Figure $1 \mathrm{~b})$ or the PARP inhibitor $\mathrm{INH}_{2} \mathrm{BP}(50$ and $100 \mu \mathrm{M})$ (Figure 1c) 1 hour before incubation with $30 \mu \mathrm{M}$ HNE partially prevented HNE-induced cell death. Next, Hoechst 33342 staining was undertaken to examine the morphological changes occurring to chondrocytes. Upon exposure to $30 \mu \mathrm{M}$ HNE, numerous chondrocytes exhibited characteristics typical of apoptosis with highly condensed nuclei (Figure 2). In contrast, very few apoptotic cells were observed in untreated cells.

\section{HNE induced caspases activation}

Caspases play important roles in the terminal execution of apoptosis induced by various stimuli. Caspase-3, -8 , and -9 activities were measured with commercial kits, and their protein cleavage was detected by Western blot analysis. Compared with untreated cells, HNE incubation resulted in a timedependent increase of caspase-8 activity (Figure 3a). HNE significantly induced caspase- 9 activity after 2,4 , and 8 hours of incubation and significantly induced caspase-3 activity after 4 and 8 hours of incubation. At 16 hours, both caspase- 3 and -9 activities were reduced to the control level (Figure 3b, c). At the protein level, 20 and $30 \mu \mathrm{M}$ HNE decreased pro-caspase$8,-9$, and -3 levels after 16 hours of incubation, probably via the cleavage process of the pro-caspase (Figure $3 d$ ). In contrast, the addition of $200 \mu \mathrm{M}$ NAC prevented the HNEinduced caspase activation.

\section{HNE affected $\mathrm{Bcl}-2$ and Bax expression and induced cytochrome $c$ release from mitochondria}

The Bcl-2 family is involved in apoptosis by regulating membrane permeability and induces cytochrome $c$ release from mitochondria into the cytosol [22-24]. To investigate the effects of HNE on Bcl-2 and Bax expression, cells were 
Figure 1

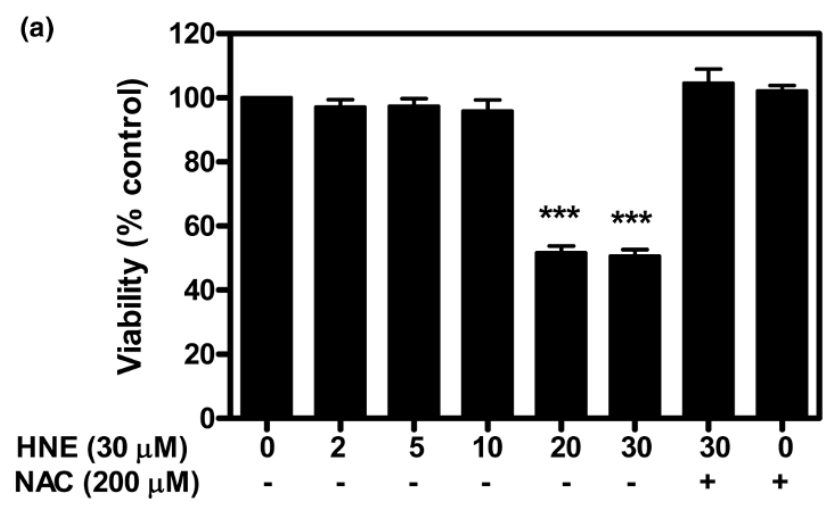

(b)

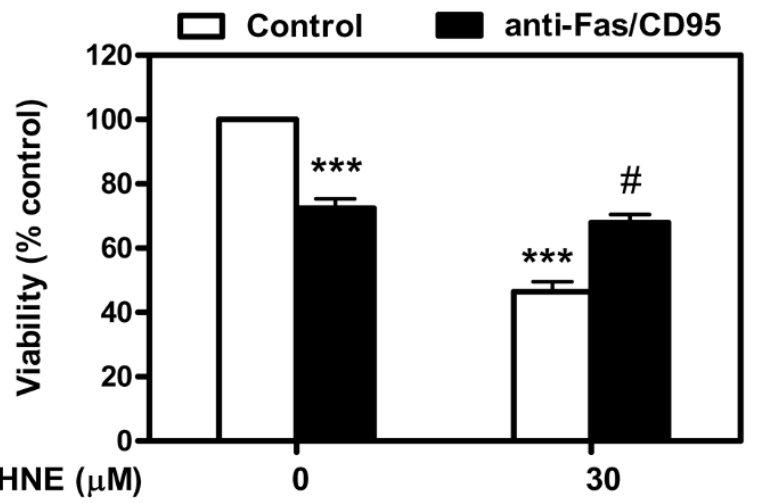

(c)

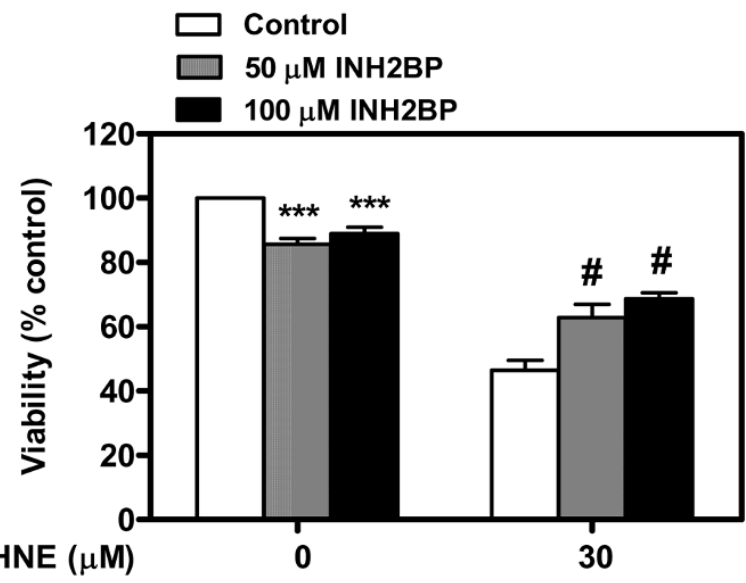

4-Hydroxynonenal (HNE)-induced cell death. (a) Chondrocytes were pre-incubated for 1 hour with or without $200 \mu \mathrm{M} \mathrm{N}$-acetyl-cysteine (NAC) followed by another incubation for 16 hours with increasing concentrations of HNE (0 to $30 \mu \mathrm{M}$ ). Chondrocytes were pre-incubated for 1 hour with or without (b) $20 \mu \mathrm{g} / \mathrm{mL}$ anti-Fas/CD95 antibody or (c) 50 and $100 \mu \mathrm{M} \mathrm{INH}{ }_{2} \mathrm{BP}$ followed by another incubation for 16 hours with or without $30 \mu \mathrm{M}$ HNE. Cell viability was evaluated by MTT assay. Data are mean \pm standard error of the mean $(n=8)$. Statistics: Student unpaired $t$ test; ${ }^{* \star \star} P<0.001$ (30 $\mu \mathrm{M}$ HNE versus untreated cells), ${ }^{\#} P<$ 0.05 (30 $\mu \mathrm{M}$ HNE+inhibitor versus $30 \mu \mathrm{M} \mathrm{HNE}$ ).
Figure 2

\section{Control}

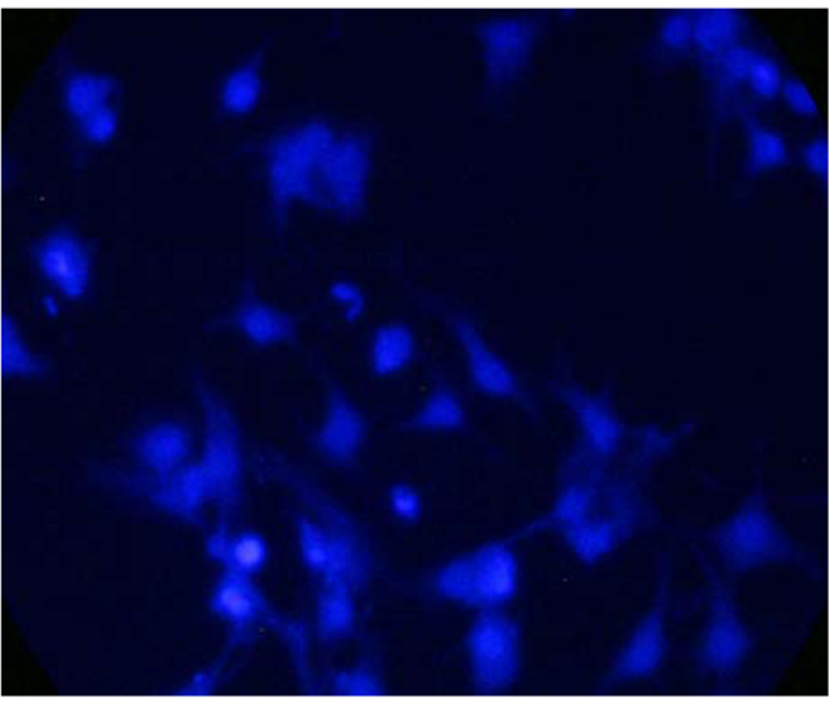

\section{$30 \mu \mathrm{M}$ HNE}

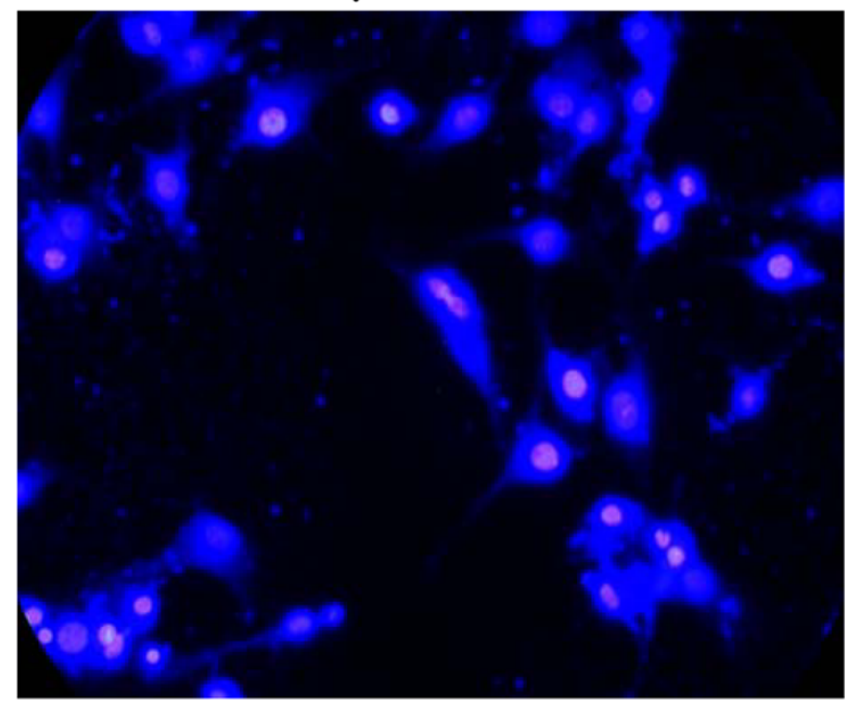

Nuclear morphology study for apoptosis. Chondrocytes were incubated for 16 hours with or without $30 \mu \mathrm{M} 4$-hydroxynonenal (HNE), stained with Hoechst 33258 , and then analyzed by fluorescence microscopy.

treated with $30 \mu \mathrm{M}$ HNE for increasing incubation times ( 0 to 16 hours) and then ELISA and Western blot experiments were performed. The level of the anti-apoptotic protein Bcl-2 was significantly decreased after 4 hours of incubation with $30 \mu \mathrm{M}$ HNE (Figure 4a). In contrast, HNE at this concentration increased the apoptotic protein Bax after 4 and 8 hours of incubation and remained elevated at 16 hours of incubation (Figure 4b). We then analyzed the effect of HNE on cyto- 
Figure 3
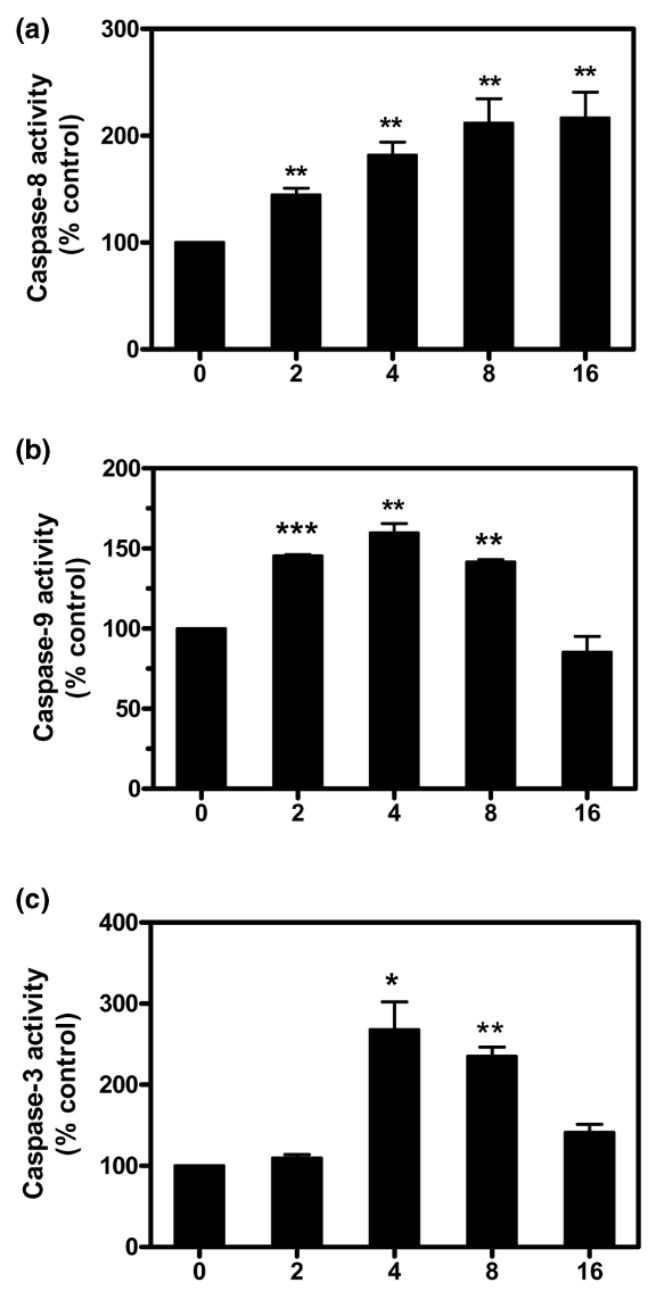

(d)

HNE $(\mu \mathrm{M})$

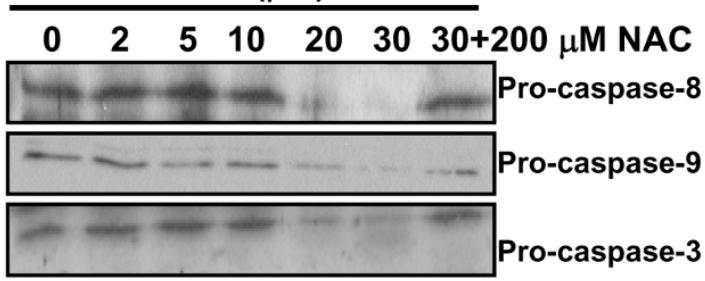

Caspase-8, -9 , and -3 activation by 4-hydroxynonenal (HNE). Chondrocytes were treated with $30 \mu \mathrm{M} \mathrm{HNE}$ for the indicated times, and enzymatic activities of caspase-8 (a), caspase- 9 (b), or caspase-3 (c) were determined with commercial kits. (d) Chondrocytes were pre-incubated for 1 hour with or without $200 \mu \mathrm{M} \mathrm{N}$-acetyl-cysteine (NAC) followed by another incubation for 16 hours with increasing concentrations of $\mathrm{HNE}$ ( 0 to $30 \mu \mathrm{M}$ ). Pro-caspase-8, pro-caspase- 9 , and pro-caspase-3 were analyzed by Western blot. Data are mean \pm standard error of the mean $(n=8)$ and expressed as a percentage of untreated cells. Statistics: Student unpaired $t$ test; ${ }^{*} P<0.05,{ }^{\star \star} P<0.01,{ }^{* \star \star} P<0.001$.
Figure 4

(a)

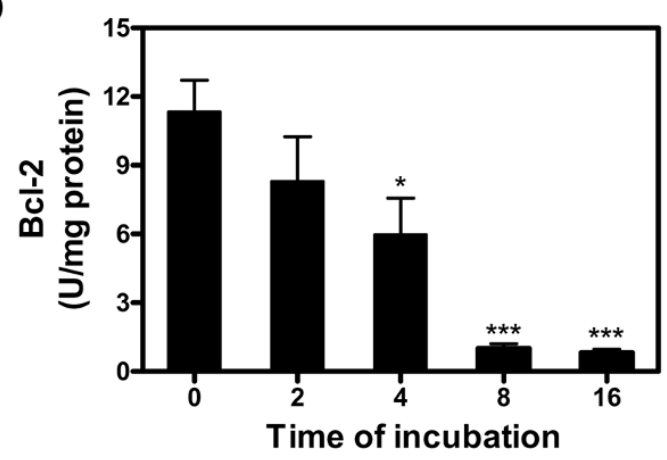

(b)

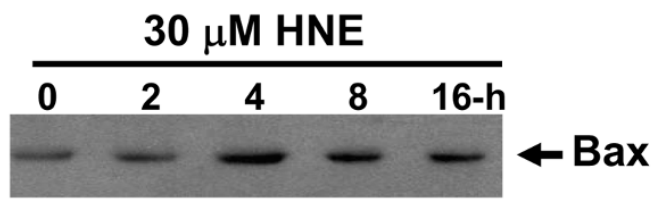

(c)

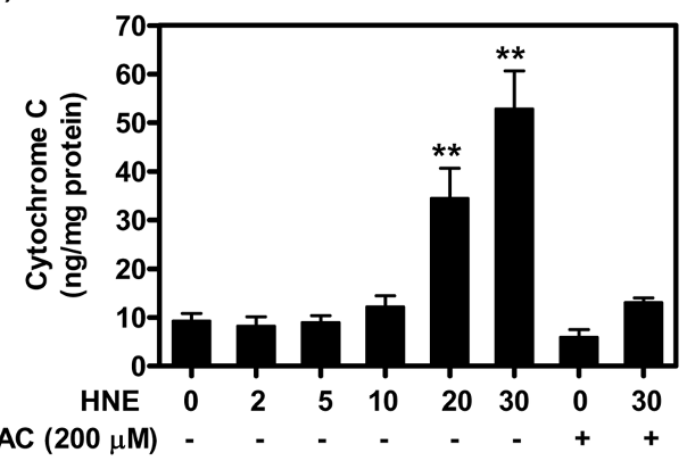

4-Hydroxynonenal (HNE) modified Bcl-2/Bax protein expression and induced cytochrome $c$ release from mitochondria. Chondrocytes were treated with $30 \mu \mathrm{M} \mathrm{HNE}$ for the indicated times and then Bcl-2 (a) and Bax (b) protein levels were determined by commercial kit and Western blot, respectively. (c) Chondrocytes were pre-incubated with or without $200 \mu \mathrm{M} \mathrm{N}$-acetyl-cysteine (NAC) for 1 hour followed by another incubation for 16 hours in the presence of increasing concentrations of HNE $(0$ to $30 \mu \mathrm{M})$. Cytochrome $c$ level was assessed in cytosolic fractions with a kit. ${ }^{\star} P<0.05,{ }^{\star \star} P<0.01,{ }^{\star \star \star} P<0.001$.

chrome $c$ release from mitochondria to the cytosol. As shown in Figure 4c, the cytochrome $c$ level in cytosolic fractions significantly increased in chondrocytes treated with 20 or $30 \mu \mathrm{M}$ HNE for 16 hours (Figure 4c). However, the pre-incubation of chondrocytes with $200 \mu \mathrm{M}$ NAC prevented HNE-induced DNA fragmentation, PARP activation, and AIF translocation to the nucleus. 
Figure 5

(a)

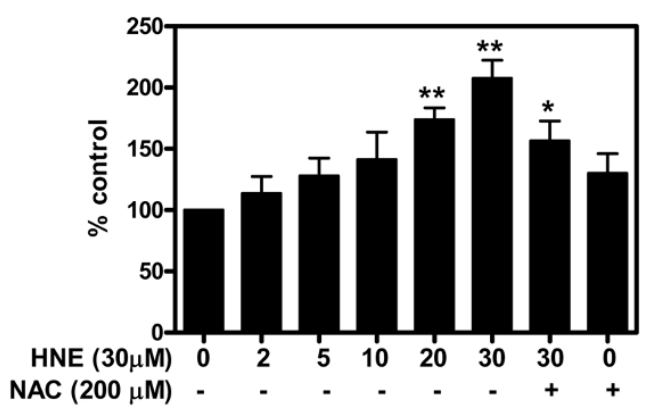

(b)

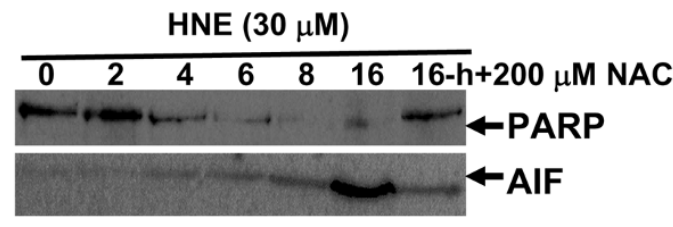

4-Hydroxynonenal (HNE) induced DNA fragmentation, poly (ADPribose) polymerase (PARP) cleavage, and apoptosis-inducing factor (AIF) translocation to the nucleus. Chondrocytes were pre-incubated for 1 hour with or without $200 \mu \mathrm{M} \mathrm{N}$-acetyl-cysteine (NAC) and then incubated for another 16 hours with $30 \mu \mathrm{M} \mathrm{HNE}$ or with increasing concentrations of HNE (0 to $30 \mu \mathrm{M}$ ). (a) The cytoplasmic histone-associated DNA fragments were quantified with a kit. (b) Chondrocytes were pre-incubated for 1 hour with or without $200 \mu \mathrm{M}$ NAC followed by another incubation with $30 \mu \mathrm{M} \mathrm{HNE}$ at different incubation times. PARP cleavage and AIF translocation in nuclear fractions were analyzed by Western blot. Data are mean \pm standard error of the mean and expressed as a percentage of untreated cells. Statistics: Student unpaired $t$ test; ${ }^{\star} P<0.05,{ }^{\star \star} P<0.01$.

HNE induced DNA fragmentation, PARP cleavage, and apoptosis-inducing factor translocation to the nucleus

Nuclear damage is very important in cell death. Therefore, we further studied the role of HNE in DNA fragmentation, PARP activation, and AIF translocation to the nucleus. Chondrocytes were exposed to HNE in the presence or absence of $200 \mu \mathrm{M}$ NAC. The extent of nuclear DNA fragmentation was measured quantitatively by ELISA. As shown in Figure $5 \mathrm{a}$, the level of cytoplasmic histone-associated DNA fragments was increased when DNAs were extracted from chondrocytes after exposure to 20 and $30 \mu \mathrm{M}$ HNE for 16 hours compared with the control. In contrast, cells pre-treated with $200 \mu \mathrm{M}$ NAC were protected against HNE-induced DNA fragmentation. PARP activation and AIF translocation to the nuclei during apoptosis are implicated on a large scale in DNA fragmentation and peripheral chromatin condensation. As shown in Figure $5 \mathrm{~b}, 30 \mu \mathrm{M}$ HNE induced PARP cleavage and AIF translocation in the nuclei after 4 hours of incubation. Moreover, pre-treatment with $200 \mu \mathrm{M}$ NAC blocked PARP cleavage and AIF translocation.
Figure 6

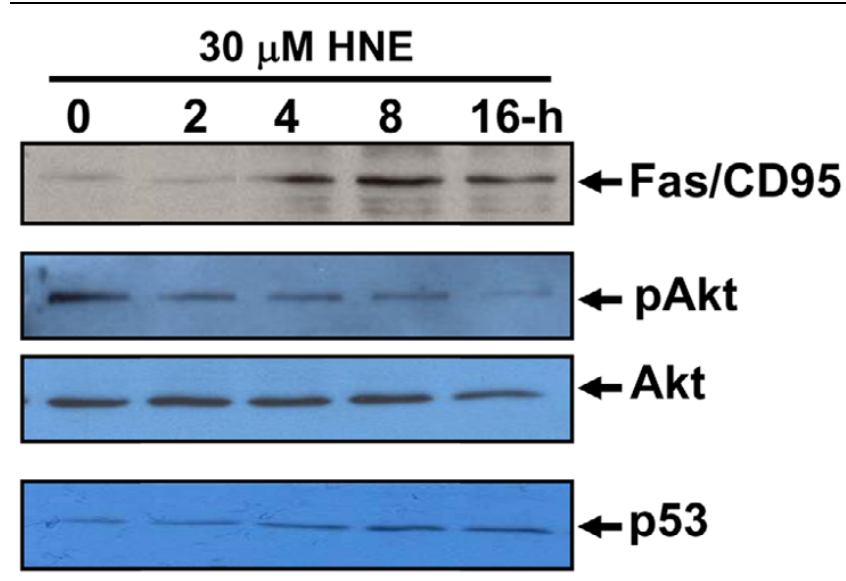

4-Hydroxynonenal (HNE) induced Fas/CD95 and p53 protein expression and reduced Akt phosphorylation. Chondrocytes were incubated with $30 \mu \mathrm{M}$ HNE for increasing incubation times. Total cell lysates or nuclear extracts $(\sim 20 \mu \mathrm{g})$ were subjected to Western analysis $(\mathrm{n}=8)$ using antibodies anti-Fas/CD95, anti-p53, anti-phospho Akt, and antitotal Akt.

\section{HNE induced Fas/CD95 and p53 expression but inhibited} Akt

To study the molecular mechanisms involved in the induction of cell death by HNE, we examined Akt activity as well as Fas/ CD95 and p53 protein expression in chondrocytes after different incubation times. Western blot analysis indicated that 30 $\mu \mathrm{M}$ HNE elicited Fas/CD95 and p53 protein expression but, in contrast, reduced survival signalling, including the phosphorylated form of Akt (Figure 6). Total Akt was unchanged.

\section{HNE altered redox status and energy metabolism}

In the next series of experiments, we determined whether the redox status and energy metabolism of chondrocytes could be implicated in part in HNE-induced cell death. As illustrated in Figure 7, $30 \mu \mathrm{M}$ HNE decreased the reduced form of GSH and the reducing equivalent, NADPH, needed for its regeneration (Figure $7 \mathrm{a}$ ), after 16 hours of incubation. We additionally established that HNE, at this concentration, evoked a significant diminution of energy depletion through inhibition of mNADP+-ICDH activity (Figure 7b), glucose uptake (Figure 7c), and intracellular ATP synthesis (Figure 7d).

\section{HNE-induced cell death is controlled by GSTA4-4 expression}

GSTA4-4 is a known aldehyde-detoxifying enzyme as has been shown by previous studies $[16,17]$. To assess the functional consequences of GSTA4-4 inhibition versus overexpression in chondrocytes, the cytotoxicity of $30 \mu \mathrm{M}$ HNE was evaluated by MTT cytotoxicity assay. First, the ablation of GSTA4-4 with GSTA4-4 siRNA in isolated chondrocytes augmented the HNE-induced cell mortality as measured by MTT assay at 4,8 , and 16 hours of incubation (Figure 8 a). These results indicate that GSTA4-4 offers a significant protection 
Figure 7

(a)

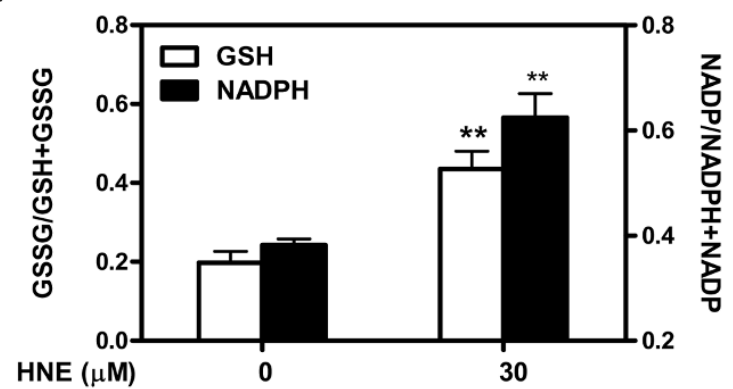

(b)

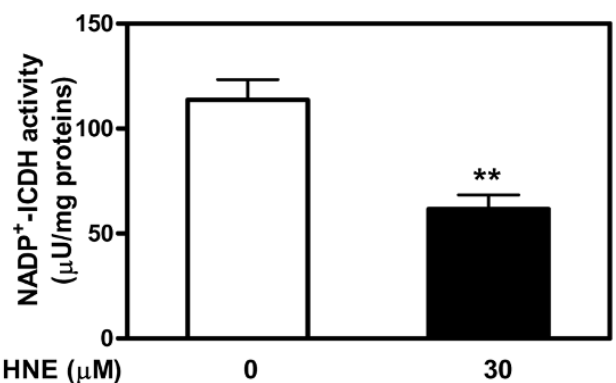

(c)

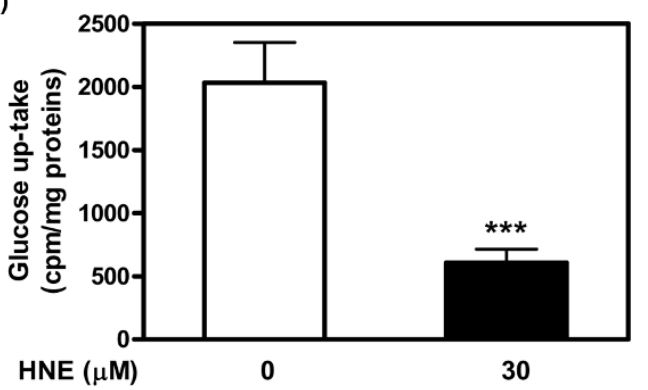

(d)

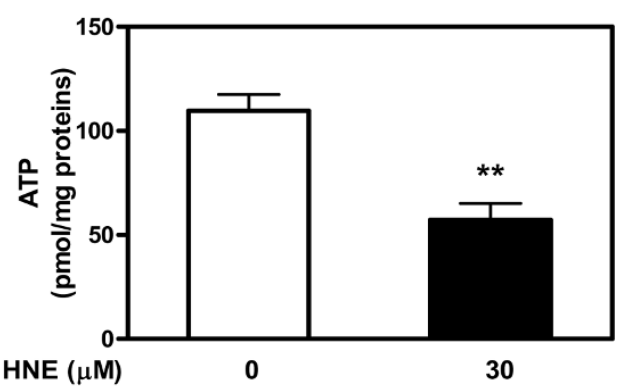

4-Hydroxynonenal (HNE) altered redox status and energy metabolism in osteoarthritis chondrocytes. Chondrocytes were treated for 16 hours with $30 \mu \mathrm{M} \mathrm{HNE}$, and cellular extracts were subjected to different analysis to determine (a) GSSG/(GSSG+GSH) and NADP/

(NADPH+NADP) ratios, (b) mNADP+-ICDH activity, (c) glucose

uptake, and (d) ATP level. Data are mean \pm standard error of the mean and expressed as a percentage of untreated cells. Statistics: Student unpaired $t$ test; ${ }^{\star \star} P<0.01,{ }^{\star \star \star} P<0.001$. GSH, glutathione; GSSG, oxidized glutathione; mNADP+-ICDH, mitochondrial NADP+-dependent isocitrate dehydrogenase.
Figure 8

(a)

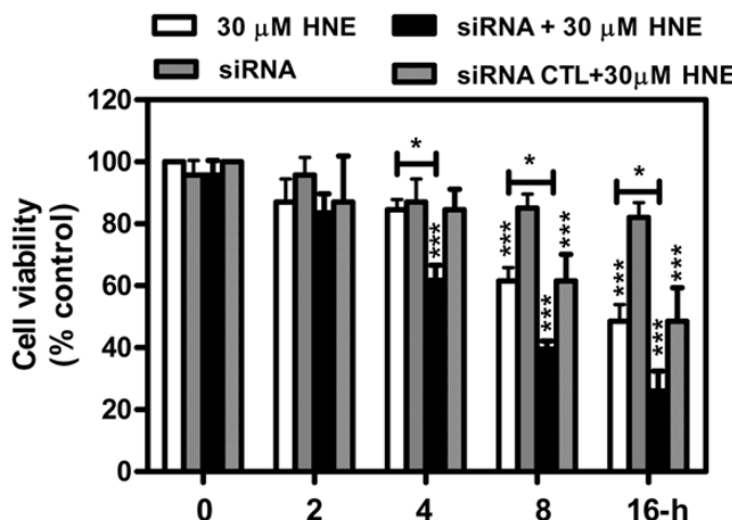

(b)

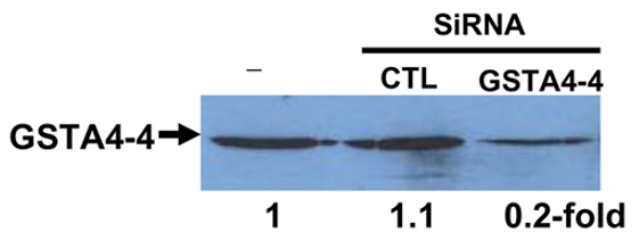

(c)

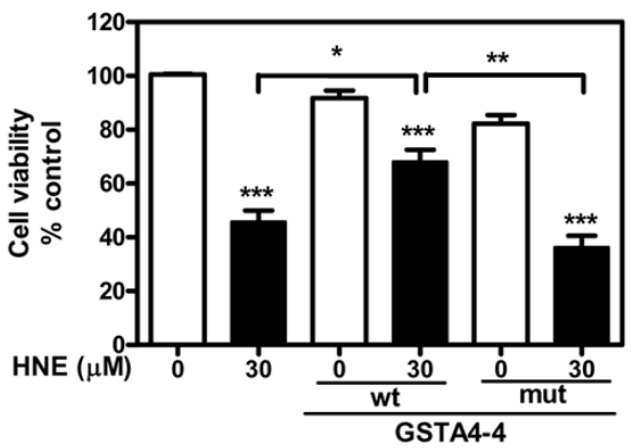

(d)

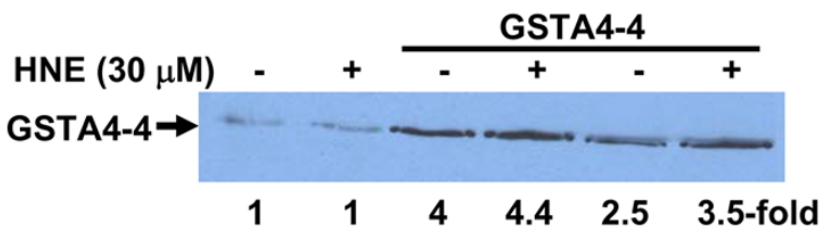

Glutathione-S-transferase A4-4 (GSTA4-4) controlled the 4-hydroxynonenal (HNE) cytotoxicity. Chondrocytes were transfected with (a) small interfering RNA (siRNA) GSTA4-4 or with (c) wild-type or mutant GSTA4-4 expression plasmids, and then cell viability was determined by MTT assay. (b) and (d) GSTA4-4 protein expression was evaluated respectively in cellular extracts of transfected chondrocytes with siRNA or expression plasmids of GSTA4-4 by Western blotting. Data are mean \pm standard error of the mean and expressed as a percentage of untreated cells. Statistics: Student unpaired $t$ test; ${ }^{\star} P<0.05,{ }^{\star \star} P<$ $0.01,{ }^{\star \star \star} P<0.001$. CTL, control; MTT, 3-(4,5-dimethylthiazol-2-yl)-2,5diphenyltetrazolium bromide; mut, mutant; wt, wild-type. 
against HNE-induced DNA damage in chondrocyte cells and that siRNA ablation of this enzyme augments the HNEinduced cell death. The increase in cell mortality in transfected chondrocytes with GSTA4-4 siRNA would be attributed to the inhibition of GSTA4-4 expression by more than $80 \%$ as compared with control siRNA (Figure 8b). Second, we tested whether the increased HNE-metabolizing capacity conferred on these cells by transfection of GSTA4-4 expression vectors could reverse the cytotoxic effects of HNE. Our data showed that GSTA4-4 overexpression provided cell resistance to direct HNE cytotoxicity (Figure 8c). Western blot analysis of cell extracts with the polyclonal antibody against GSTA4-4 revealed a strong band in cellular extracts of chondrocytes transfected with GSTA4-4 and a weak signal in untransfected cells (Figure 8d).

\section{Discussion}

There is growing evidence that HNE, generated during the LPO process, is an efficient cell signalling molecule and considered as a key mediator of oxidative stress-induced pathophysiological effects. In fact, by modulating the expression of different genes, HNE exhibits a wide array of biological activities, including signal transduction, gene expression, and modulation of cell proliferation [13]. In particular, the relevance of HNE to joint biology and pathology is now becoming clearer. In our previous study, we reported, for the first time, that HNE was significantly increased in synovial fluids of OA patients and in OA chondrocytes treated with ROS donors [18]. We demonstrated that $10 \mu \mathrm{M}$ HNE affects Col II and MMP-13 at the transcriptional and post-translational levels, indicating that HNE could play a role in cartilage degradation in OA. In a second study, we identified two distinct mechanisms of HNE action in OA chondrocytes, which included upregulation of COX-2 via ATF/CRE activation and iNOS inhibition via NF- $\kappa B$ inactivation [19]. In the present study, we evaluated the potential role of $\mathrm{HNE}$ at high concentrations in the apoptotic process in OA chondrocytes. With the ultimate goal of clarifying this role, we documented the ability of HNE to modulate markers of apoptosis, redox status, and energy metabolism of chondrocytes. Then, we investigated the potential role of the HNE-metabolizing enzyme, GSTA4-4, in the control of chondrocyte death. To date, no data have demonstrated the effect of HNE on apoptotic signalling in OA.

In the present study, we reported morphological and biochemical evidence implicating HNE in the induction of chondrocyte apoptosis in a dose- and time-dependent manner, and this effect could be inhibited by NAC addition. First, we observed that HNE up to $10 \mu \mathrm{M}$ did not alter cell viability but equal or greater than to $20 \mu \mathrm{M}, \mathrm{HNE}$ was cytotoxic and significantly decreased cell viability (up to 50\%) and induced chromatin condensation, compared with untreated cells. Pre-treatment of cells with anti-Fas/CD95 or PARP inhibitor partially reduced cell mortality, suggesting a role for Fas/CD95 and PARP in HNE-inducing cell death. Second, in investigating the classi- cal markers of apoptosis, we obtained data showing that HNE induced caspase-8, -9 , and -3 activities and cleavage, AIF and cytochrome $c$ release from mitochondria, PARP activation, and DNA fragmentation. These effects were prevented by NAC. A major question arising with regard to apoptosis in general is whether the apoptotic response of chondrocytes to HNE requires upregulation of pro-apoptotic protein synthesis or whether it relies on pre-existing apoptotic machinery. Our data show that the apoptotic response of chondrocytes to $\mathrm{HNE}$ is associated with decreased $\mathrm{Bcl}-2$ expression and increased Bax expression. This suggests that chondrocytes need to modulate the synthesis of at least several anti- and pro-apototic factors to be able to undergo apoptosis when stimulated by HNE. It is noteworthy that HNE is capable of inducing apoptosis in several cell types, including hepatic cells, murine alveolar macrophages, RAW 264.7 cells, neurons as well as colonic cancer cells $[15,25,26]$. It is well documented that these cells upregulate pro-apoptotic factors (for example, caspases, PARP, Bax, and Bcl-2) to undergo apoptosis in response to HNE. The DNA fragmentation evoked by HNE required PARP activation and AIF translocation in the nucleus $[27,28]$. Moreover, our data disclosed that HNEinduced apoptosis in chondrocytes needed the induction of p53 and Fas/CD95 protein expression in a time-dependent manner. These data are in concordance with those in the literature suggesting that HNE can induce apoptosis in various cells through the death receptor Fas/CD95-mediated extrinsic pathway as well as through the p53-dependent intrinsic pathway $[29,30]$. The induction of Fas/CD95 by HNE was subsequently followed by the activation of JNKs, caspase 3 , and the onset of apoptosis in human lens epithelial cells [29]. However, the induction of p53 by HNE remains unclear. In RAW 264.7 cells, Haynes and colleagues [25] reported that HNEinduced apoptosis was not associated with p53 accumulation. This suggests that the apoptosis process elicited by HNE could vary in different cell types due to changes in the availability or sensitivity of specific regulatory pathways that are activated by the aldehyde.

Investigation of the molecular mechanisms of HNE-induced apoptosis in OA chondrocytes showed that HNE reduced serine/theonine kinase Akt activity. It has also been established that HNE-induced apoptosis leads to the inhibition of Akt phosphorylation. Akt activation results in the phosphorylation of numerous other proteins involved in the regulation of glucose metabolism, cell proliferation, apoptosis, cell migration, and gene expression [31]. HNE is definitely able to interfere with Akt activity, but so far the available findings appear, at least in part, to be contradictory. In fact, Liu and colleagues [32] reported that HNE $(20 \mu \mathrm{M})$ induced apoptosis in human T-cell leukemia Jurkat cells through impairment of the Aktmediated cell survival pathway.

The next set of experiments was focused on analyzing redox status and cell metabolism in apoptotic chondrocytes. Signifi- 
cant inhibition of cellular GSH pools, mNADP+-ICDH activity, glucose uptake, and ATP level was observed. Liu and colleagues [27] actually showed that exogenously added HNE quickly reduced cellular GSH levels in human T-lymphoma Jurkat cells. Parallelling the change in GSH levels, GSSG levels decreased, suggesting that $\mathrm{HNE}$ is directly reacting with $\mathrm{GSH}$ for consumption rather than acting as a source of pro-oxidants to simply promote GSH/GSSG exchange. It is, however, also possible that HNE decreased the GSH pool through inhibition of GSH synthesis. In any case, pre-treatment of cells with antioxidants, such as cysteine, NAC, and dithiothreitol, inhibited the action of HNE to reduce the GSH/GSSG pool, supporting the view that $\mathrm{SH}$ group-reactive HNE activity is primarily important for the observed event. On the other hand, the inhibition of mNADP+-ICDH, an important regulator of the citric acid cycle, by HNE supports the role of this aldehyde in the alteration of energy metabolism in different cell types as reported by the literature data. Our previous study revealed that mNADP+ICDH was considered as a potential target for HNE binding [33]. This key enzyme in cellular defence against oxidative damage supplies NADPH in the mitochondria needed for the regeneration of mitochondrial GSH [34]. In the present study, we further demonstrated HNE cytotoxicity in chondrocytes presumably via ATP depletion caused by the inhibition of mitochondrial respiratory enzymes and glucose uptake. Glucose serves as the major energy substrate for articular chondrocytes and as the main precursor for the synthesis of ECM glycosaminoglycans in cartilage $[35,36]$. The inhibition of proteoglycan synthesis in OA chondrocytes by HNE (data not shown) could be attributed to glucose uptake blockage observed in the present work. ATP is the main energy source for cellular proliferation, differentiation, and apoptosis [37,38]. Kanwar and colleagues [39] demonstrated that cellular ATP depletion markedly decreased the synthesis of sulfated proteoglycans by a mechanism that was normalized by increasing cellular ATP levels.

To determine whether HNE-metabolizing enzymes played a role in chondrocyte apoptosis, we conducted additional experiments to show that the changes in GSTA4-4 expression could have an impact in HNE-induced cell death. In chondrocytes, GSTA4-4 ablation with GSTA4-4 siRNA augmented the cytotoxic effect of HNE as determined by MTT assay. In contrast, the overexpression of this enzyme in chondrocytes offered significant protection against HNE-induced cell cytotoxicity. These data concur with a previous report indicating that accelerated HNE metabolism in HL-60 and K562 human erythroleukemia cells overexpressing GSTA4-4 blocks/delays apoptosis triggered by HNE $[16,17]$. Increased HNE-metabolizing capacity in GSTA4-4-transfected cells appeared to result in an increased rate of proliferation as well as decreased cell death by preventing PARP and caspase activation. Transfection of GSTA4-4 also protected against cytotoxic $\mathrm{H}_{2} \mathrm{O}_{2}$ cytotoxicity to a similar degree, an effect that could be ascribed either to the direct enzymatic detoxification of $\mathrm{H}_{2} \mathrm{O}_{2}$ through the GSH-peroxidase activity of GSTA4-4 or to increased metabolism via GSH conjugation of $\mathrm{HNE}$ formed as a consequence of $\mathrm{H}_{2} \mathrm{O}_{2}$ exposure.

\section{Conclusion}

In this study, we identified, for the first time, a novel mechanism linking oxidative stress to apoptosis signalling in OA chondrocytes through the action of HNE, an LPO end product. Our data suggest that the increased level of HNE in articular tissue may contribute to OA development via its ability to alter cellular viability and the metabolic activity of chondrocytes. In the light of previous data on decreased GSTA4-4 activity in patients with OA, particular interest should be addressed to the pathophysiological role of this enzyme in OA development.

\section{Competing interests}

The authors declare that they have no competing interests.

\section{Authors' contributions}

FV performed the experimental study, contributed to the preparation of the manuscript, and undertook the statistical analysis. HF, PL, and JCF evaluated and interpreted the data and assisted with the preparation of the manuscript. QS assisted in the experiments and in the isolation of chondrocytes from human cartilage. PR provided cartilage specimens and participated to the study design. MB designed the study, supervised the project, evaluated and interpreted the data, and prepared the manuscript. All authors read and approved the final manuscript.

\section{Acknowledgements}

The authors thank Dr Sanjay Awasthi for the generous gift of the GSTA4-4 expression plasmids. This study was supported by the Arthritis Society and Fonds de la recherche en santé du Québec (FRSQ) (grant 5330). MB is a research scholar at the FRSO.

\section{References}

1. Poole AR: An introduction to the pathophysiology of osteoarthritis. Front Biosci 1999, 4:D662-D670.

2. Sandell $L J$, Aigner T: Articular cartilage and changes in arthritis. An introduction: cell biology of osteoarthritis. Arthritis Res 2001, 3:107-113.

3. Blanco FJ, Guitian R, Vazquez-Martul E, de Toro FJ, Galdo F: Osteoarthritis chondrocytes die by apoptosis. A possible pathway for osteoarthritis pathology. Arthritis Rheum 1998, 41:284-289.

4. Kim HA, Lee YJ, Seong SC, Choe KW, Song YW: Apoptotic chondrocyte death in human osteoarthritis. J Rheumatol 2000 , 27:455-462.

5. Mistry D, Oue Y, Chambers MG, Kayser MV, Mason RM: Chondrocyte death during murine osteoarthritis. Osteoarthritis Cartilage 2004, 12:131-141.

6. Hashimoto S, Ochs RL, Komiya S, Lotz M: Linkage of chondrocyte apoptosis and cartilage degradation in human osteoarthritis. Arthritis Rheum 1998, 41:1632-1638.

7. Murrell GA, Jang D, Williams RJ: Nitric oxide activates metalloprotease enzymes in articular cartilage. Biochem Biophys Res Commun 1995, 206:15-21.

8. Taskiran D, Stefanovic-Racic M, Georgescu H, Evans C: Nitric oxide mediates suppression of cartilage proteoglycan synthesis by interleukin-1. Biochem Biophys Res Commun 1994, 200:142-148.

9. Blanco FJ, Ochs RL, Schwarz H, Lotz M: Chondrocyte apoptosis induced by nitric oxide. Am J Pathol 1995, 146:75-85. 
10. Del CM Jr, Loeser RF: Nitric oxide-mediated chondrocyte cell death requires the generation of additional reactive oxygen species. Arthritis Rheum 2002, 46:394-403.

11. Hashimoto S, Takahashi K, Amiel D, Coutts RD, Lotz M: Chondrocyte apoptosis and nitric oxide production during experimentally induced osteoarthritis. Arthritis Rheum 1998, 41:1266-1274

12. Esterbauer $\mathrm{H}$, Schaur RJ, Zollner $\mathrm{H}$ : Chemistry and biochemistry of 4-hydroxynonenal, malonaldehyde and related aldehydes. Free Radic Biol Med 1991, 11:81-128.

13. Poli G, Schaur RJ, Siems WG, Leonarduzzi G: 4-Hydroxynonenal: a membrane lipid oxidation product of medicinal interest. Med Res Rev 2008, 28:569-631.

14. Barrera G, Pizzimenti S, Laurora S, Briatore F, Toaldo C, Dianzani MU: 4-hydroxynonenal and cell cycle. Biofactors 2005, 24:151-157.

15. Cerbone A, Toaldo C, Laurora S, Briatore F, Pizzimenti S, Dianzani MU, Ferretti C, Barrera G: 4-Hydroxynonenal and PPARgamma ligands affect proliferation, differentiation, and apoptosis in colon cancer cells. Free Radic Biol Med 2007, 42:1661-1670.

16. Cheng JZ, Singhal SS, Saini M, Singhal J, Piper JT, Van Kuijk FJ, Zimniak P, Awasthi YC, Awasthi S: Effects of mGST A4 transfection on 4-hydroxynonenal-mediated apoptosis and differentiation of K562 human erythroleukemia cells. Arch Biochem Biophys 1999, 372:29-36.

17. Cheng JZ, Singhal SS, Sharma A, Saini M, Yang Y, Awasthi S, Zimniak $P$, Awasthi YC: Transfection of mGSTA4 in HL-60 cells protects against 4-hydroxynonenal-induced apoptosis by inhibiting JNK-mediated signaling. Arch Biochem Biophys 2001, 392:197-207.

18. Morquette B, Shi Q, Lavigne P, Ranger P, Fernandes JC, Benderdour M: Production of lipid peroxidation products in osteoarthritic tissues: new evidence linking 4-hydroxynonenal to cartilage degradation. Arthritis Rheum 2006, 54:271-281.

19. Vaillancourt $F$, Morquette $B$, Shi $Q$, Fahmi H, Lavigne $P$, Di Battista $\mathrm{JA}$, Fernandes JC, Benderdour M: Differential regulation of cyclooxygenase-2 and inducible nitric oxide synthase by 4hydroxynonenal in human osteoarthritic chondrocytes through ATF-2/CREB-1 transactivation and concomitant inhibition of NF-kappaB signaling cascade. J Cell Biochem 2007, 100:1217-1231.

20. Altman R, Asch E, Bloch D, Bole G, Borenstein D, Brandt $K$, Christy W, Cooke TD, Greenwald R, Hochberg M: Development of criteria for the classification and reporting of osteoarthritis. Classification of osteoarthritis of the knee. Diagnostic and Therapeutic Criteria Committee of the American Rheumatism Association. Arthritis Rheum 1986, 29:1039-1049.

21. Mosmann T: Rapid colorimetric assay for cellular growth and survival: application to proliferation and cytotoxicity assays. $J$ Immunol Methods 1983, 65:55-63.

22. Cory S, Adams JM: The Bcl2 family: regulators of the cellular life-or-death switch. Nat Rev Cancer 2002, 2:647-656.

23. Rosse T, Olivier R, Monney L, Rager M, Conus S, Fellay I, Jansen $\mathrm{B}$, Borner $\mathrm{C}$ : Bcl-2 prolongs cell survival after Bax-induced release of cytochrome $c$. Nature 1998, 391:496-499.

24. Kluck RM, Bossy-Wetzel E, Green DR, Newmeyer DD: The release of cytochrome $c$ from mitochondria: a primary site for Bcl-2 regulation of apoptosis. Science 1997, 275:1132-1136.

25. Haynes RL, Brune B, Townsend AJ: Apoptosis in RAW 264.7 cells exposed to 4-hydroxy-2-nonenal: dependence on cytochrome $C$ release but not p53 accumulation. Free Radic Biol Med 2001, 30:884-894.

26. Peng ZF, Koh CH, Li OT, Manikandan J, Melendez AJ, Tang SY, Halliwell B, Cheung NS: Deciphering the mechanism of HNEinduced apoptosis in cultured murine cortical neurons: transcriptional responses and cellular pathways. Neuropharmacology 2007, 53:687-698.

27. Liu W, Kato M, Akhand AA, Hayakawa A, Suzuki $H$, Miyata $T$, Kurokawa K, Hotta Y, Ishikawa N, Nakashima I: 4-hydroxynonenal induces a cellular redox status-related activation of the caspase cascade for apoptotic cell death. J Cell Sci 2000, 113:635-641.

28. Ramachandran V, Perez A Chen J, Senthil D Schenker S, Henderson GI: In utero ethanol exposure causes mitochondrial dysfunction, which can result in apoptotic cell death in fetal brain: a potential role for 4-hydroxynonenal. Alcohol Clin Exp Res 2001, 25:862-871.
29. Li J, Sharma R, Patrick B, Sharma A, Jeyabal PV, Reddy PM, Saini MK, Dwivedi S, Dhanani S, Ansari NH, Zimniak P, Awasthi S, Awasthi YC: Regulation of CD95 (Fas) expression and Fasmediated apoptotic signaling in HLE B-3 cells by 4-hydroxynonenal. Biochemistry 2006, 45:12253-12264.

30. Awasthi YC, Sharma R, Sharma A, Yadav S, Singhal SS, Chaudary $\mathrm{P}$, Awasthi S: Self-regulatory role of 4-hydroxynonenal in signaling for stress-induced programmed cell death. Free Radic Biol Med 2008, 45:111-118.

31. Brazil DP, Hemmings BA: Ten years of protein kinase $B$ signalling: a hard Akt to follow. Trends Biochem Sci 2001 26:657-664.

32. Liu W, Akhand AA, Takeda $K$, Kawamoto $Y$, Itoigawa $M$, Kato $M$, Suzuki H, Ishikawa N, Nakashima I: Protein phosphatase 2Alinked and -unlinked caspase-dependent pathways for downregulation of Akt kinase triggered by 4-hydroxynonenal. Cell Death Differ 2003, 10:772-781.

33. Benderdour M, Charron G, Deblois D, Comte B, Des Rosiers C: Cardiac mitochondrial NADP+-isocitrate dehydrogenase is inactivated through 4-hydroxynonenal adduct formation: an event that precedes hypertrophy development. J Biol Chem 2003, 278:45154-45159.

34. Jo SH, Son MK, Koh HJ, Lee SM, Song IH, Kim YO, Lee YS, Jeong KS, Kim WB, Park JW, Song BJ, Huh TL: Control of mitochondrial redox balance and cellular defense against oxidative damage by mitochondrial NADP+-dependent isocitrate dehydrogenase. J Biol Chem 2001, 276:16168-16176.

35. Wang J, Zhou J, Bondy CA: Igf1 promotes longitudinal bone growth by insulin-like actions augmenting chondrocyte hypertrophy. FASEB J 1999, 13:1985-1990.

36. Mobasheri A, Vannucci SJ, Bondy CA, Carter SD, Innes JF, Arteaga MF, Trujillo E, Ferraz I, Shakibaei M, Martin-Vasallo P: Glucose transport and metabolism in chondrocytes: a key to understanding chondrogenesis, skeletal development and cartilage degradation in osteoarthritis. Histol Histopathol 2002, 17:1239-1267.

37. Agresti C, Meomartini ME, Amadio S, Ambrosini E, Volonte C Aloisi F, Visentin S: ATP regulates oligodendrocyte progenitor migration, proliferation, and differentiation: involvement of metabotropic P2 receptors. Brain Res Brain Res Rev 2005, 48:157-165

38. Bernardi P, Scorrano L, Colonna R, Petronilli V, Di Lisa F: Mitochondria and cell death. Mechanistic aspects and methodological issues. Eur J Biochem 1999, 264:687-701.

39. Kanwar Y, Yoshinaga Y, Liu Z, Wallner E, Carone F: Biosynthetic regulation of proteoglycans by aldohexoses and ATP. Proc Natl Acad Sci USA 1992, 89:8621-8625. 